\title{
1 ANTIOXIDANT RESPONSES FOLLOWING ACTIVE AND PASSIVE SMOKING OF TOBACCO AND
}

2 ELECTRONIC CIGARETTES

3

4 Konstantina Poulianiti ${ }^{1,2}$, Christina Karatzaferi ${ }^{1,2}$, Andreas D. Flouris ${ }^{1,2}$, Ioannis G. Fatouros ${ }^{1,2}$, Yiannis $5 \quad$ Koutedakis $^{1,2,3}$, Athanasios Z. Jamurtas $\mathrm{s}^{1,2}$

6

$7{ }^{1}$ Department of Physical Education \& Sport Science, University of Thessaly, Karies, Trikala 42100, Greece.

$8{ }^{2}$ Institute of Research and Technology Thessaly, Centre for Research and Technology Hellas, Trikala, 9 Greece.

$10{ }^{3}$ School of Sports, Performing Arts and Leisure, University of Wolverhampton, United Kingdom. 11

12 CORRESPONDING AUTHOR:

13 Athanasios Z. Jamurtas

14 Department of Physical Education \& Sport Science

15 University of Thessaly

16 Karies, Trikala 42100, Greece, Tel: +30 24310 47054; Fax: +30 2431047054

17 E-mail: ajamurt@pe.uth.gr

18

19

20 Keywords: oxidative stress; redox status; glutathione; secondhand smoke; free radicals. 


\section{ABSTRACT}

22 Context: It has been indicated that acute active and passive tobacco cigarette smoking may cause 23 changes on redox status balance that may result in significant pathologies. However, no study has 24 evaluated the effects of active and passive e-cigarette smoking on redox status of consumers.

25 Objective: To examine the acute effects of active and passive e-cigarette and tobacco cigarette smoking 26 on selected redox status markers.

27 Methods: Using a randomized single-blind crossover design, 30 participants (15 smokers and 15 non28 smokers) were exposed to three different experimental conditions. Smokers underwent a control 29 session, an active tobacco cigarette smoking session (smoked 2 cigarettes within $30-\mathrm{min}$ ) and an active 30 e-cigarette smoking session (smoked a pre-determined number of puffs within 30-min using a liquid 31 with $11 \mathrm{ng} / \mathrm{ml}$ nicotine). Similarly, non- smokers underwent a control session, a passive tobacco 32 cigarette smoking session (exposure of 1 hour to $23 \pm 1 \mathrm{ppm}$ of $\mathrm{CO}$ in a $60 \mathrm{~m}^{3}$ environmental chamber) 33 and a passive e-cigarette smoking session (exposure of 1 hour to air enriched with pre- determined 34 number of puffs in a $60 \mathrm{~m}^{3}$ environmental chamber). Total antioxidant capacity (TAC), catalase activity 35 (CAT) and reduced glutathione (GSH) were assessed in participants' blood prior to, immediately after, 36 and 1-hour post-exposure. Results: TAC, CAT and GSH remained similar to baseline levels immediately

37 after and 1-hour-post exposure $(p>0.05)$ in all trials. Conclusions: Tobacco and e-cigarette smoking 38 exposure do not acutely alter the response of the antioxidant system, neither under active nor passive 39 smoking conditions. Overall, there is not distinction between tobacco an e-cigarette active and passive 40 smoking effects on specific redox status indices. 


\section{INTRODUCTION}

42 During the past decade, a new product has been introduced in the tobacco smoking substitutes market, 43 called electronic cigarette (e-cigarette) (Flouris and Oikonomou, 2010, Etter et al., 2011). The e-cigarette

44 is an electronic nicotine delivery device which consists of a rechargeable battery, an evaporator and 45 disposable filters (Flouris and Oikonomou, 2010, Etter et al., 2011). Due to lack of research on the safety 46 of e-cigarettes, the World Health Organization called for intensified research assessing the health effects

47 of e-cigarette use (World Health Organisation, 2010). Addressing this call, several studies have been 48 recently conducted on e-cigarettes. Some of these studies showed that the levels of tobacco-specific 49 toxicants in e-cigarette can be $9-450$ times lower than in tobacco cigarette smoke (Goniewicz et al., 50 2014), supporting the role of e-cigarettes in reducing harm from tobacco smoking. However, other 51 studies report that e-cigarette 'vaping' introduces new dangers. For example, it has been reported that a 52 high toxicity component, diethylene glycol, was detected in the liquid of e-cigarettes, albeit in 53 "approved" levels (Varlet et al., 2015). Additionally, substances like polycyclic aromatic hydrocarbons 54 and carcinogenic nitrosamines have been detected in some e-cigarette liquids (Pisinger and Dossing, 55 2014). Overall, the presence of such toxic agents appears to be brand-specific, as researchers examining 56 other brands found no traces of toxic or carcinogenic substances (Leondiadis, 2009). The above and 57 other conflicting reports have prompted calls for effective regulation and promotion of e-cigarette as 58 substitutes to tobacco smoking for existing smokers (Etter et al., 2011, Farsalinos and Le Houezec, 2015), 59 especially given the appeal of e-cigarettes to adolescents (Dutra and Glantz, 2014).

60 Oxidative stress reflects an imbalance between the systemic manifestation of free radicals and 61 the biological system's ability to detoxify these reactive intermediates or to repair the resulting damage 62 (Sies and Cadenas, 1985). This redox imbalance may cause toxic effects that damage all components of 63 the cell including proteins, lipids and nucleic acids. Thus, oxidative stress is thought to be involved in the 
64 development of several diseases such as cancer, cardiovascular disease, Parkinson's disease, Alzheimer's

65 disease and chronic fatigue syndrome (Sies and Cadenas, 1985). Reports indicate that the acute and long

66 term (i.e., chronic) effects of active and passive tobacco cigarette smoking may attenuate the

67 antioxidant defense system response which can, in turn, generate long-term pathologies (Valkonen and

68 Kuusi, 1998, Scheffler et al., 1992). For example, increased lipid peroxidation and protein modification

69 due to smoking has been reported extensively in the literature when smokers were compared to non-

70 smokers (Pignatelli et al., 2001, Petruzzelli et al., 1997). Even though the exact mechanism that links

71 smoking with the development of atherosclerosis and damage to the vascular wall is still unclear,

72 evidence suggests that oxidants delivered by the tar and the gas phase become deposited in the lung

73 and also are delivered directly to the plasma and the vasculature and therefore activating enzymes

74 responsible for pro-oxidant development in the vascular wall (Heitzer et al., 2000). Furthermore, 75 damage to the vasculature can occur due to activation of neutrophils, monocytes, platelets, and T cells.

76 In addition, endothelial dysfunction that is present in active and passive smokers is augmented by the

77 antioxidant vitamin $\mathrm{C}$, indicating that oxidative stress plays a crucial role in that phenomenon (Heitzer et 78 al., 2000).

79 Currently, the effects of active and passive e-cigarette smoking on redox status remain

80 unknown. Evaluating the human redox status response to active and passive e-cigarette smoking may

81 aid in the understanding of oxidative stress contribution to the development of smoking-related 82 diseases. Therefore, the aim of this investigation was to examine the acute effects of active and passive 83 e-cigarette and tobacco cigarette smoking on selected redox status markers. Based on the 84 aforementioned findings that e-cigarettes may generate a reduced disruption in different body systems, 85 it was hypothesized that the acute effects of active and passive e-cigarette smoking on redox status 86 would be less pronounced as compared to active and passive tobacco cigarette smoking. 
88 MATERIALS AND METHODS

\section{Participants}

90 The experimental protocol was approved by the Ethics Committee of the Department of Physical

91 Education and Sports Science at the University of Thessaly. Two groups of healthy adult volunteers

92 participated and signed a written consent after being informed of all risks and benefits of the study. One

93 group consisted of 15 smokers ( $\geq 15$ cigarettes / day; 8 men; 7 women; $36.8 \pm 9.9$ years; BMI 25.6 \pm 4.1

$94 \mathrm{~kg} / \mathrm{m}^{2}$ ) and another group consisted of 15 non-smokers (8 men; 7 women; $28.87 \pm 10.5$ years; BMI

$9523.6 \pm 3.0 \mathrm{~kg} / \mathrm{m}^{2}$ ). Exclusion criteria included acute illness, cardiovascular diseases, intake of medication

96 or antioxidant supplements, pregnancy and previous use of e-cigarette by smokers. For non-smokers,

97 smoking was an additional exclusion criterion.

98

99 Study Design and Procedures

100 Participants in each group (active smokers and passive non-smokers) underwent three different 101 experimental sessions that were performed in a random order (separated by a minimum of seven days).

102 Participants were required to avoid food for 10 hours, strenuous physical activity for 72 hours and 103 smoking or exposure to smoke during the night prior to the measurements. This study was part of a 104 larger study and the procedures followed are described in detail elsewhere (Flouris et al., 2013). 105

106 Active smokers

107 Active smokers underwent a control session $\left(\mathrm{AS}_{\mathrm{CON}}\right)$, an active tobacco cigarette smoking session ( $\left.\mathrm{AS}_{\mathrm{TOB}}\right)$ 108 and an active e- cigarette smoking session $\left(\mathrm{AS}_{\mathrm{E}-\mathrm{CIG}}\right)$. Blood samples were collected prior to, immediately 109 after, as well as one hour after the smoking sessions. During the $\mathrm{AS}_{\mathrm{CON}}$ session, participants were asked 
110 to draw puffs on a non-lit cigarette of their own brand, for 30 minutes. In the $\mathrm{AS}_{\text {Tов }}$ session participants 111 smoked two tobacco cigarettes of their own brand within 30 minutes. During the $\mathrm{AS}_{\mathrm{E}-\mathrm{CIG}}$ session, 112 participants smoked a certain number of puffs on an e-cigarette (device: GIANT, NOBACCO GP, Greece) 113 within 30 minutes. The e-cigarette liquid (NOBACCO USA MIX, NOBACCO GP, Greece) used, had tobacco 114 taste and contained $11 \mathrm{mg} / \mathrm{ml}$ nicotine. The specific e-cigarette and liquid was selected for the study due 115 to the fact that this liquid was the only one in Greece that had been previously analyzed by an 116 independent publicly-funded Research Institute and consisted of $>60 \%$ propylene glycol, $<10 \%$ nicotine, $117<5 \%$ linalool, $<5 \%$ tobacco essence and $<1 \%$ methyl vanilyn (Leondiadis, 2009). A previously-developed 118 equation (Flouris et al., 2013) was used to calculate the number of e-cigarette puffs to ensure that the 119 amount of nicotine entering the human body would be equivalent to the amount of nicotine inhaled 120 when smoking a tobacco cigarette: [( $\mathrm{mg}$ of nicotine in own brand of tobacco cigarettes $\times 1.5 \times 50) / 11] \times$ 1212.

\section{Passive non-smokers}

124 Non-smokers underwent a control session $\left(\mathrm{PS}_{\mathrm{CON}}\right)$, a passive tobacco cigarette smoking session $\left(\mathrm{PS}_{\mathrm{TOB}}\right)$ 125 and a passive e-cigarette smoking session ( $\left.\mathrm{PS}_{\mathrm{E}-\mathrm{CIG}}\right)$. Blood samples were collected prior to, immediately 126 after, as well as one hour after the smoking sessions, as previously described (Flouris et al., 2013). 127 Briefly, in the $\mathrm{PS}_{\text {CON }}$ session, participants were asked to remain for 1 hour in a $60 \mathrm{~m}^{3}$ environmental 128 chamber (air temperature: $21^{\circ} \mathrm{C}$; air velocity: $0.05 \mathrm{~m} / \mathrm{sec}$; humidity: $45 \%$ ) while breathing normal air. In 129 the $\mathrm{PS}_{\text {Тов }}$ session, participants were exposed in the same chamber for 1 hour to air polluted with 130 tobacco cigarette smoke at a CO concentration of $23 \pm 1 \mathrm{ppm}$, that is similar to the one at bar/restaurant 131 levels (CO90 $\mathrm{CO}-\mathrm{CO}_{2}$ analyzer, Martindale Electric Ltd., Watford, UK). The required concentration of the 132 gas mixture was achieved by combustion of cigarettes from several popular brands using an air pump 
133 (DYN, Volos, Greece), which regulated the airflow at $4 \mathrm{~L} / \mathrm{min}$. Cigarettes were half smoked using the air 134 pump, then they were left lit for 2 min to generate sidestream smoke, and then the rest of the cigarettes 135 were smoked via the air pump. An average of $29.2 \pm 0.9$ cigarettes was smoked in order to achieve the 136 required level of $\mathrm{CO}$ in the exposure chamber. In the $\mathrm{PS}_{\mathrm{E}-\mathrm{CIG}}$ session, participants were exposed to air 137 polluted with e-cigarette vapour for one hour in the same chamber. In this case, the air was polluted by 138 smoking e-cigarettes (device and liquid same as those used during the $\mathrm{AS}_{\mathrm{E}-\mathrm{CIG}}$ session) via the same air 139 pump set at an air flow rate of $4 \mathrm{~L} / \mathrm{min}$ for the same time as in the $\mathrm{PS}_{\text {Тов }}$ session.

141 Blood Collection and Handling

142 Blood samples $(5 \mathrm{ml})$ were collected from each antecubital vein and were placed into EDTA-containing 143 tubes (20 $\mu \mathrm{lETDA} / \mathrm{ml}$ of blood). In order to obtain plasma, samples were centrifuged immediately at $1441,370 \times \mathrm{g}$, at $4^{\circ} \mathrm{C}$ for $10 \mathrm{~min}$. The supernatant plasma was collected, aliquoted in Eppendorf tubes, stored 145 at $-80^{\circ} \mathrm{C}$ and thawed only once before analyzed for total antioxidant capacity (TAC). Red blood cells 146 lysate was produced by diluting packed erythrocytes with distilled water (1:1 vol:vol). The mixture was 147 inverted vigorously and centrifuged at $4,000 \times \mathrm{g}$, at $4^{\circ} \mathrm{C}$ for $15 \mathrm{~min}$. The supernatant was collected and 148 aliquoted in Eppendorf tubes, stored at $-80^{\circ} \mathrm{C}$ and thawed only once before analyzed for reduced 149 glutathione (GSH) and catalase activity (CAT). Finally, in order to obtain serum, another portion of blood 150 sample $(5 \mathrm{ml})$ was collected and placed into separate tubes containing clot activator, left for 20 min to 151 clot at room temperature, and centrifuged at $1,370 \mathrm{xg}$, at $4^{\circ} \mathrm{C}$ for $10 \mathrm{~min}$. The supernatant was collected 152 and aliquoted in Eppendorf tubes, stored at $-80^{\circ} \mathrm{C}$ and thawed only once before analyzed for cotinine. 153 154 Assays 
155 Procedures used to assess cotinine levels in circulating blood are described elsewhere (Flouris et al., 156 2013). Reduced glutathione concentration was determined using previous methodology (Reddy et al., 157 2004). Briefly, $500 \mu \mathrm{l}$ of red blood cells lysate was treated with $500 \mu \mathrm{l} \mathrm{TCA} 5 \%$, centrifuged at $16000 \times \mathrm{g}$, 158 at $4^{\circ} \mathrm{C}$ for $10 \mathrm{~min} .300 \mu \mathrm{l}$ of the supernatant was collected and added in $90 \mu \mathrm{l} \mathrm{TCA} \mathrm{5 \% ,} \mathrm{centrifuged} \mathrm{at}$ $15916000 \times \mathrm{g}$, at $4^{\circ} \mathrm{C}$ for $10 \mathrm{~min}$. Thereafter, $20 \mu \mathrm{l}$ of the TCA treated supernatant was mixed with $660 \mu \mathrm{l}$ of $16067 \mathrm{mM}$ sodium-potassium phosphate (pH 7.95) and $330 \mu \mathrm{l}$ of $1 \mathrm{mM} \mathrm{5,5'-Dithiobis} \mathrm{(2-nitrobenzoic} \mathrm{acid)}$ 161 (DTNB). The samples were incubated in the dark at room temperature for $45 \mathrm{~min}$ and the absorbance 162 was read at $412 \mathrm{~nm}$ using a spectrophotometer. The GSH concentration was calculated by standard 163 curve constructed using commercially available standards.

164 Catalase activity was measured according to the Aebi assay (Aebi, 1984). Briefly, $4 \mu \mathrm{l}$ of red 165 blood cells lysate (diluted 1:10) were added to 2,991 $\mu \mathrm{l}$ of $67 \mathrm{mM}$ sodium-potassium phosphate buffer $166\left(\mathrm{pH} \mathrm{7.4)}\right.$ and the samples were incubated at $37^{\circ} \mathrm{C}$ for $10 \mathrm{~min}$. The sample was transferred into a glass 167 cuvette, $5 \mu \mathrm{l}$ of $30 \%$ hydrogen peroxide was added and the change in absorbance was immediately read 168 at $240 \mathrm{~nm}$ for $90 \mathrm{sec}$.

169 Total Antioxidant Capacity was determined according to Janaszewska \& Bartosz assay 170 (Janaszewska and Bartosz, 2002), based on the scavenging of 2,2-diphenyl-1 picrylhydrazyl (DPPH) free 171 radical. DPPH stock solution $(10 \mathrm{mM})$ was prepared by dissolving $0.02 \mathrm{~g} \mathrm{DPPH}$ in $5 \mathrm{ml}$ of methanol and mix 172 in the stirrer. The working solution was obtained by diluting stock solution 100 times with methanol. 173 Afterwards, $20 \mu \mathrm{l}$ of plasma was mixed with $480 \mu \mathrm{l}$ of $10 \mathrm{mM}$ sodium-potassium phosphate $(\mathrm{pH} 7.4)$ and $174500 \mu \mathrm{l}$ of $0.1 \mathrm{M}$ working solution (DPPH). The samples were incubated in the dark for $30 \mathrm{~min}$ at room 175 temperature, centrifuged at $20,000 \times \mathrm{g}$, at $25^{\circ} \mathrm{C}$ for $3 \mathrm{~min}$. $900 \mu \mathrm{l}$ of the supernatant was transferred 176 into a clean plastic cuvette and the absorbance was read at $520 \mathrm{~nm}$ using a spectrophotometer. TAC is 177 presented as mM of DPPH reduced to 2,2-diphenyl-1 picrylhydrazine (DPPH:H). 

Intra-assay correlation coefficient for GSH, CAT and TAC were $3.5 \%, 2.8 \%$ and $2.2 \%$, respectively.

\section{Statistical Analysis}

181 Based on data from a previously-published study (Flouris, 2009), the resulting minimum required sample 182 size for this study was eight participants per group, providing a reliability rate of $95 \%$. To reduce the 183 probability of making a type II error, 15 participants were recruited for each group (smokers and non184 smokers). Normality was assessed by the Kolmogorov-Smirnov test and the distribution of all variables 185 was not found significantly different from normal. A two-way (trial $\times$ time) ANOVA with repeated 186 measures of time was used to assess differences between the three conditions in smokers and non187 smokers. Furthermore, a two way (condition $\mathrm{x}$ time) ANOVA was used to assess differences between the 188 passive and active condition. The level of statistical significance was set at $p<0.05$. Data are presented as 189 mean \pm SD. The SPSS version 15.0 (SPSS Inc., USA) was used for all analyses.

\section{RESULTS}

\section{Active Smoking}

193 No changes were observed in GSH (Figure 2A), CAT (Figure 3A), and TAC (Figure 4A) concentrations prior 194 to, immediately after and 1-hour after the exposure to $A S_{T O B}, A_{E-C I G}$ and $A S_{C O N}(p>0.05)$. Furthermore, no 195 interaction between the three conditions was revealed for any time point of assessment in any of the 196 three variables (GSH, CAT, TAC) assessed ( $p>0.05$ ). Specifically, GSH ( $\mu \mathrm{mol} / \mathrm{g} \mathrm{Hb}$ ) levels for $\mathrm{AS}_{\text {Tов }}$ were $1972.21 \pm 0.85$ prior to, $2.11 \pm 0.76$ immediately after, and $1.72 \pm 0.82$ one hour after the smoking sessions, 198 respectively. During $\mathrm{AS}_{\mathrm{E}-\mathrm{CI},}, \mathrm{GSH}$ levels were $2.07 \pm 1.25$ prior to, $2.17 \pm 0.87$ immediately after, and $1992.26 \pm 0.86$ one hour after the smoking sessions, respectively. Finally, GSH levels for $\mathrm{AS}_{\mathrm{CON}}$ were $1.65 \pm 0.87$ 200 prior to, $1.80 \pm 1.06$ immediately after, and $1.92 \pm 1.28$ one hour after the smoking sessions, respectively. 
201 CAT $\left(\mu \mathrm{mol} / \mathrm{min} / \mathrm{mg} \mathrm{Hb}\right.$ ) activity for $\mathrm{AS}_{\text {ТОв }}$ was $347 \pm 33$ prior to, $332 \pm 14$ immediately after, and $389 \pm 43$ 202 one hour after the smoking sessions, respectively. Also, CAT activity for $\mathrm{AS}_{\mathrm{E}-\mathrm{CIG}}$ was $357 \pm 14$ prior to, $203331 \pm 55$ immediately after, and $354 \pm 29$ one hour after the smoking sessions, respectively. Finally, CAT 204 activity for $\mathrm{AS}_{\text {CON }}$ was $338 \pm 53$ prior to, $349 \pm 66$ immediately after, and $329 \pm 51$ one hour after the 205 smoking sessions, respectively. TAC (mM DPPH) levels for $\mathrm{AS}_{\text {Tов }}$ were $1.03 \pm 0.09$ prior to, $1.01 \pm 0.09$ 206 immediately after and $0.99 \pm 0.09$ one hour after the smoking sessions, respectively. During $\mathrm{AS}_{\mathrm{E}-\mathrm{CIG}, \mathrm{TAC}}$ 207 levels were $0.98 \pm 0.14$ prior to, $0.96 \pm 0.11$ immediately after, and $0.95 \pm 0.12$ one hour after the smoking 208 sessions, respectively. Finally, TAC levels for $\mathrm{AS}_{\mathrm{CON}}$ were $1.04 \pm 0.08$ prior to, $1.00 \pm 0.10$ immediately after, 209 and $1.01 \pm 0.09$ one hour after the smoking sessions, respectively.

211 Passive Smoking

212 No time-dependent changes were found in GSH (Figure 2B), CAT (Figure 3B), and TAC (Figure 4B) 213 concentration prior to, immediately after and one hour after the exposure to $\mathrm{PS}_{\mathrm{TOB}}, \mathrm{PS}_{\mathrm{E}-\mathrm{CIG}}$ and $\mathrm{PS}_{\mathrm{CON}}$ 214 ( $p>0.05)$. No interaction between the three conditions was revealed for any time point of assessment in 215 any of the three variables (GSH, CAT, TAC) assessed ( $p>0.05)$. Specifically, GSH ( $\mu \mathrm{mol} / \mathrm{g} \mathrm{Hb}$ ) levels for $216 \mathrm{PS}_{\text {Tов }}$ were $2.08 \pm 1.02$ prior to, $1.65 \pm 0.66$ immediately after, and $1.53 \pm 0.81$ one hour after the smoking 217 sessions, respectively. During $\mathrm{PS}_{\mathrm{E}-\mathrm{CIG}} \mathrm{GSH}$ levels were $2.35 \pm 1.20$ prior to, $2.65 \pm 0.81$ immediately after, 218 and $2.78 \pm 1.18$ one hour after the smoking sessions, respectively. Finally, GSH levels for PS Con $_{\text {were }}$ $2191.68 \pm 0.85$ prior to, $1.42 \pm 0.97$ immediately after, and $1.51 \pm 0.94$ one hour after the smoking sessions, 220 respectively. CAT ( $\mu \mathrm{mol} / \mathrm{min} / \mathrm{mgHb})$ activity for $\mathrm{PS}_{\text {Тов }}$ was $385 \pm 53$ prior to, $382 \pm 45$ immediately after, 221 and $377 \pm 41$ one hour after the smoking sessions, respectively. Also, CAT activity for PS $S_{E-C I G}$ was $331 \pm 60$ 222 prior to, $326 \pm 50$ immediately after, and $354 \pm 72$ one hour after the smoking sessions, respectively. 223 Finally, CAT activity for $\mathrm{PS}_{\text {CON }}$ was $357 \pm 90$ prior to, $330 \pm 56$ immediately after, and $327 \pm 60$ one hour after 
224 the smoking sessions, respectively. TAC (mM DPPH) levels for $\mathrm{PS}_{\text {Тов }}$ were $1.03 \pm 0.16$ prior to, $1.04 \pm 0.17$

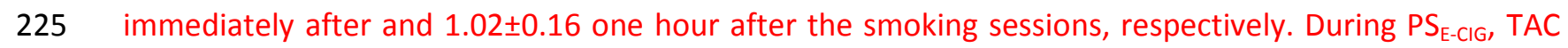

226 levels were $1.03 \pm 0.16$ prior to, $1.06 \pm 0.18$ immediately after, and $1.04 \pm 0.13$ one hour after the smoking

227 sessions, respectively. Finally, TAC levels for $\mathrm{PS}_{\text {Con }}$ were $1.00 \pm 0.18$ prior to, $0.97 \pm 0.14$ immediately after, 228 and $0.99 \pm 0.17$ one hour after the smoking sessions, respectively.

229

230 DISCUSSION

231 To our knowledge, this is the first study to examine the acute effects of active and passive e-cigarette 232 smoking on the antioxidant response in human blood. The results indicate that active and passive 233 smoking of e-cigarettes and tobacco cigarettes does not result in immediately visible perturbations of 234 the blood antioxidant system as evaluated by GSH, CAT and TAC.

236 Active Smoking

237 Previous research indicates that active smoking may have detrimental effects on human health (Flouris 238 et al., 2010). Tobacco smoking accounts for the largest amount of deaths and disability years in high239 income countries and is the third leading cause of death and disabilities in developing countries (Lopez 240 et al., 2006). Tobacco contains several substances that may influence the human physiology and has 241 been linked to oxidative stress development (Halliwell and Poulsen, 2006). Since the number of deaths is 242 mounting and the economic burden is escalating in the recent years, new products have been 243 introduced in the market to counteract the negative effects of smoking. Electronic cigarette is one of 244 them and some studies indicate that cotinine levels are similar to the one found after tobacco smoking 245 (Flouris et al., 2013). 
Smoking either e-cigarettes or conventional tobacco cigarettes may disrupt human health. A

247 recent in vitro study showed that tobacco and e-cigarette products may initiate an inflammatory 248 response and oxidative stress production in Kupffer cells in the liver (Rubenstein et al., 2015). 249 Furthermore, short-term e-cigarette "vaping" generates smaller changes in lung function compared to 250 tobacco cigarette smoking (Flouris et al., 2013, Vardavas et al., 2011). However, inhaling an e-cigarette 251 for 5 min results in attenuated exhaled nitric oxide levels (Vardavas et al., 2011, Marini et al., 2014). 252 Changes in peripheral flow resistance due to acute narrowing of the diameter of the peripheral 253 pathways and lower levels of nitric oxide have been proposed as possible mechanisms for the changes in 254 exhaled nitric oxide levels following either tobacco or e-cigarette smoking (Vardavas et al., 2011). Nitric 255 oxide, besides having an important role in several physiological processes of the respiratory tract, has 256 been used as a marker for assessing oxidative stress (Hoyt et al., 2003).

257 In the literature, several studies have assessed the antioxidant status of healthy smokers. 258 According to Moriarty et al (Moriarty et al., 2003) a significant decrease in GSH levels in plasma of 259 smokers compared to non smokers, was found. However, regarding the activities of three of the most 260 significant antioxidant enzymes, superoxide dismutase (SOD), glutathione peroxidise (GPx) and CAT, 261 contradictory results were found. Another study (Zhou et al., 2000) observed decreased activity of 262 these enzymes in erythrocytes of smokers compared to non smokers. Yildiz et al (Yildiz et al., 2002), 263 found decreased CAT and SOD activities, however, GPx activity remained unchanged in erythrocytes of 264 smokers compared to non smokers, On the other hand, increased activities of these enzymes were 265 observed in the erythrocytes of young smokers compared to age-matched non smokers (Ozguner et al., 266 2005), reflecting that the small duration of smoking perhaps was not efficient to alter their enzymatic 267 antioxidant response. Finally, Meta et al (Metta et al., 2015), assessed the erythrocyte antioxidant 268 defense against cigarette smoking, finding that there was highly significant difference in SOD activity, in 
269

270

271

272

274

275

276

277

278

279

280

281

282

283

284

285

286

287

288

289

290

291

comparison to CAT and GPx between smokers and non smokers. Indeed, while CAT and GPx activities were found decreased, SOD activity was found increased in smokers compared to non smokers. TAC was also assessed in blood of smokers and non smokers and was found unchanged in the study of Kurku et al (Kurku et al., 2015) and decreased in smokers in the study of Mojtaba et al (Mojtaba et al., 2014)

In the study of Kurku et al (Kurku et al., 2015) acute effects of smoking on antioxidant defense were also assessed. Specifically, saliva samples were collected from smokers $1 \mathrm{~h}$ after smoking only one cigarette. Nevertheless, no difference in the levels of TAC, SOD and GPx was observed pre and before smoking. The short period of exposure to only one cigarette, was not enough to cause antioxidant defense modifications. The aforementioned attenuation of exhaled nitric oxide levels following active ecigarette and tobacco cigarette smoking may suggest changes in redox status. However, we did not observe any statistically significant acute changes in antioxidant levels either in time or between groups. We scrutinized our data further by examining our data as percentage of initial value, to account for subject variability (data not shown) without again finding statistically significant alterations in antioxidant levels. Perhaps the oxidative stress does not stem from a reduction in antioxidant capacity but from an increase in oxidants. Moreover, the tissue assessed may play a role. In this study we assessed changes in the antioxidant system in blood and red blood cells lysate (to systemic oxidative status) whereas the exhaled nitric oxide levels assessed in previous studies indicates airway oxidative stress. Additionally, we restricted our study to the immediate effects of smoking on antioxidant levels. Therefore, we cannot exclude that reductions in antioxidant capacity could be revealed if sampling was repeated some hours after the exposure. Further studies are needed to elucidate possible differences in the redox response between tissues, especially following active e-cigarette smoking. 
292 Chronic exposure to passive tobacco smoking has been shown to generate unfavourable health effects

293 (Faught et al., 2009, Carrillo et al., 2009) since it increases the risk of heart disease by approximately

$29430 \%$ whereas acute exposure (minutes to hours) has nearly as large effects as chronic active smoking

295 (Metsios et al., 2007, Dinas et al., 2011, Barnoya and Glantz, 2005). The negative health effects of

296 tobacco passive smoking are exemplified by acute unfavorable effects on lung function, cytokine

297 production, thyroid hormone secretion, and complete blood count parameters (Dinas et al., 2014,

298 Flouris et al., 2008, Metsios et al., 2007). Chronic exposure to passive tobacco smoking has been also 299 shown to result in changes in redox balance. Exposure to chronic passive smoking results in a $63 \%$ 300 increase in 8-hydroxy-2'-deoxyguanosine in the blood of exposed subjects and $13 \%$ and $37 \%$ increase in 301 catalase and glutathione peroxidase activity, respectively (Howard et al., 1998). Furthermore, a strong 302 association between serum protein carbonyl and malondialdehyde concentration has been revealed in 303 non-smoker patients hospitalized for acute myocardial infarction (Megson et al., 2013). Yildiz et al (Yildiz 304 et al., 2002), evaluated the erythrocyte antioxidant defence of passive smokers and found significantly 305 decreased CAT and SOD activities in passive smokers in comparison to non smokers. Based on these 306 findings, it is clear that exposure of chronic passive tobacco smoking can lead to changes in redox status. 307 However, there is only a limited number of interventional studies that assessed oxidative stress 308 responses following a single exposure to passive smoking. These studies indicate that acute passive 309 tobacco smoking results in airway acidification, oxidative stress, and decreased levels of FeNO (Flouris et 310 al., 2013, Kostikas et al., 2013). Furthermore, significant increases have been reported in 8-isoprostane 311 levels after $30 \mathrm{~min}$ of passive smoking, an increase that was equivalently to the levels of smokers (Kato 312 et al., 2006). These results are in contrast with the current findings of no changes in redox status 313 markers neither immediately post nor 1-hour post exposure. Possible reasons for this contradiction 314 might be that we assessed components of the antioxidant system whereas the previous studies assessed 
315 markers of oxidative stress. Furthermore, two of the three aforementioned studies assessed oxidative

316 stress in lungs. We assessed systemic oxidative stress in molecules found in the blood which may not

317 reflect lung tissue levels, or may require some time before any changes are observed.

318 Acute exposure to passive e-cigarette environments has been shown to increase cotinine levels

319 to an extent similar to that of passive tobacco cigarette smoking (Flouris et al., 2013). However, passive

320 e-cigarette vapour exposure shows no significant changes in lung function (Flouris et al., 2013).

321 Furthermore, passive e-cigarette vapour exposure does not appear to influence the results of the 322 complete blood count examination (Flouris et al., 2012). The present results indicate that a 1-hour 323 exposure to a passive e-cigarette environment does not cause significant perturbations in the 324 antioxidant system up to 1-hour post-exposure. It is possible that changes would become evident if we 325 had continued our observation for a longer period. Finally, as our measurements indicate systemic redox 326 status, we cannot exclude alterations at the level of the lung epithelial cells, as observed in a mouse 327 study (Lerner et al., 2015).

328 It is important to note that, while we instructed our subjects to consume similar meals in the 329 day prior to each assessment, we did not strictly monitor their diet. High levels of food and/or high 330 activity of other endogenous antioxidants may explain the lack of responses in the antioxidant system 331 following the active or passive smoking procedures. This is because the bioavailability of the antioxidant 332 vitamin C changes following smoking whereas its turnover in smokers is $40 \%$ higher compared to non333 smokers (German Nutrition, 2015).

\section{CONCLUSION}

In conclusion, we found that tobacco and e-cigarette smoking exposure do not acutely alter the 337 response of the antioxidant system, neither under active nor passive smoking conditions. Overall, there 
1

2

3

4

5

6

7

8

9

10

11

12

13

14

15

16

17

18

19

20

21

22

23

24

25

26

27

28

29

30

31

32

33

34

35

36

37

38

39

40

41

42

43

44

45

46

47

48

49

50

51

52

53

54

55

56

57

58

59

60
338 is not distinction between tobacco and e-cigarette active and passive smoking effects on specific redox 339 status indices. 


\section{REFERENCES}

341

342

343

344

345

346

347

348

349

350

351

352

353

354

355

356

357

358

359

360

361

362

363

364

365

366

367

368

369

370

371

372

373

374

375

376

377

378

379

380

381

382

AEBI, H. 1984. Catalase in vitro. Methods Enzymol, 105, 121-6.

BARNOYA, J. \& GLANTZ, S. A. 2005. Cardiovascular effects of secondhand smoke: nearly as large as smoking. Circulation, 111, 2684-98.

CARRILLO, A. E., METSIOS, G. S. \& FLOURIS, A. D. 2009. Effects of secondhand smoke on thyroid function. Inflamm Allergy Drug Targets, 8.

DINAS, P. C., KOUTEDAKIS, Y. \& FLOURIS, A. D. 2011. Effects of active and passive tobacco cigarette smoking on heart rate variability. Int J Cardiol, 163, 109-115.

DINAS, P. C., METSIOS, G. S., JAMURTAS, A. Z., TZATZARAKIS, M. N., WALLACE HAYES, A., KOUTEDAKIS, Y., TSATSAKIS, A. M. \& FLOURIS, A. D. 2014. Acute effects of second-hand smoke on complete blood count. Int J Environ Health Res, 24, 56-62.

DUTRA, L. M. \& GLANTZ, S. A. 2014. Electronic cigarettes and conventional cigarette use among U.S. adolescents: a cross-sectional study. JAMA Pediatr, 168, 610-7.

ETTER, J. F., BULLEN, C., FLOURIS, A. D., LAUGESEN, M. \& EISSENBERG, T. 2011. Electronic nicotine delivery systems: a research agenda. Tob Control, 20, 243-8.

FARSALINOS, K. E. \& LE HOUEZEC, J. 2015. Regulation in the face of uncertainty: the evidence on electronic nicotine delivery systems (e-cigarettes). Risk Manag Healthc Policy, 8, 157-67.

FAUGHT, B. E., FLOURIS, A. D. \& CAIRNEY, J. 2009. Epidemiological evidence associating secondhand smoke exposure with cardiovascular disease. Inflamm Allergy Drug Targets, 8.

FLOURIS, A. D., CHORTI, M. S., POULIANITI, K. P., JAMURTAS, A. Z., KOSTIKAS, K., TZATZARAKIS, M. N., WALLACE HAYES, A., TSATSAKIS, A. M. \& KOUTEDAKIS, Y. 2013. Acute impact of active and passive electronic cigarette smoking on serum cotinine and lung function. Inhal Toxicol, 25, 91101.

FLOURIS, A. D., METSIOS, G. S., JAMURTAS, A. Z. \& KOUTEDAKIS, Y. 2008. Sexual dimorphism in the acute effects of secondhand smoke on thyroid hormone secretion, inflammatory markers and vascular function. Am J Physiol Endocrinol Metab, 294, E456-62.

FLOURIS, A. D., METSIOS, G. S., JAMURTAS, A. Z. \& KOUTEDAKIS, Y. 2010. Cardiorespiratory and immune response to physical activity following exposure to a typical smoking environment. Heart, 96, 860-4.

FLOURIS, A. D. \& OIKONOMOU, D. N. 2010. Electronic cigarettes: miracle or menace? BMJ, 340, c311.

FLOURIS, A. D., POULIANITI, K. P., CHORTI, M. S., JAMURTAS, A. Z., KOURETAS, D., OWOLABI, E. O., TZATZARAKIS, M. N., TSATSAKIS, A. M. \& KOUTEDAKIS, Y. 2012. Acute effects of electronic and tobacco cigarette smoking on complete blood count. Food Chem Toxicol, 50, 3600-3603.

GERMAN NUTRITION, S. 2015. New Reference Values for Vitamin C Intake. Ann Nutr Metab, 67, 13-20.

GONIEWICZ, M. L., KNYSAK, J., GAWRON, M., KOSMIDER, L., SOBCZAK, A., KUREK, J., PROKOPOWICZ, A., JABLONSKA-CZAPLA, M., ROSIK-DULEWSKA, C., HAVEL, C., JACOB, P., 3RD \& BENOWITZ, N. 2014. Levels of selected carcinogens and toxicants in vapour from electronic cigarettes. Tob Control, 23, 133-9.

HALLIWELL, B. B. \& POULSEN, H. E. 2006. Cigarette smoke and oxidative stress, Berlin, Germany, Springer-Verlag.

HEITZER, T., BROCKHOFF, C., MAYER, B., WARNHOLTZ, A., MOLLNAU, H., HENNE, S., MEINERTZ, T. \& MUNZEL, T. 2000. Tetrahydrobiopterin improves endothelium-dependent vasodilation in chronic smokers : evidence for a dysfunctional nitric oxide synthase. Circ Res, 86, E36-41. 
HOWARD, D. J., BRIGGS, L. A. \& PRITSOS, C. A. 1998. Oxidative DNA damage in mouse heart, liver, and lung tissue due to acute side-stream tobacco smoke exposure. Arch Biochem Biophys, 352, 293 7.

HOYT, J. C., ROBBINS, R. A., HABIB, M., SPRINGALL, D. R., BUTTERY, L. D., POLAK, J. M. \& BARNES, P. J. 2003. Cigarette smoke decreases inducible nitric oxide synthase in lung epithelial cells. Exp Lung Res, 29, 17-28.

JANASZEWSKA, A. \& BARTOSZ, G. 2002. Assay of total antioxidant capacity: comparison of four methods as applied to human blood plasma. Scand J Clin Lab Invest, 62, 231-6.

KATO, T., INOUE, T., MOROOKA, T., YOSHIMOTO, N. \& NODE, K. 2006. Short-term passive smoking causes endothelial dysfunction via oxidative stress in nonsmokers. Can J Physiol Pharmacol, 84, 523-9.

KOSTIKAS, K., MINAS, M., NIKOLAOU, E., PAPAIOANNOU, A. I., LIAKOS, P., GOUGOURA, S., GOURGOULIANIS, K. I., DINAS, P. C., METSIOS, G. S., JAMURTAS, A. Z., FLOURIS, A. D. \& KOUTEDAKIS, Y. 2013. Secondhand smoke exposure induces acutely airway acidification and oxidative stress. Respir Med, 107, 172-9.

KURKU, H., KACMAZ, M., KISA, U., DOGAN, O. \& CAGLAYAN, O. 2015. Acute and chronic impact of smoking on salivary and serum total antioxidant capacity. J Pak Med Assoc, 65, 164-9.

LEONDIADIS, L. 2009. Results of chemical analyses in NOBACCO electronic cigarette refills [Online]. Athens, Greece: Mass Spectrometry and Dioxin Analysis Lab, National Center for Scientific Research "Demokritos". Available: http://www.nobacco.gr/datafiles/files/DIMOKRITOS.pdf [Accessed October 19 2009].

LERNER, C. A., SUNDAR, I. K., YAO, H., GERLOFF, J., OSSIP, D. J., MCINTOSH, S., ROBINSON, R. \& RAHMAN, I. 2015. Vapors produced by electronic cigarettes and e-juices with flavorings induce toxicity, oxidative stress, and inflammatory response in lung epithelial cells and in mouse lung. PLoS One, 10, e0116732.

LOPEZ, A. D., MATHERS, C. D., EZZATI, M., JAMISON, D. T. \& MURRAY, C. J. L. 2006. Global burden of disease and risk factors, New York, USA, The World Bank and Oxford University Press.

MARINI, S., BUONANNO, G., STABILE, L. \& FICCO, G. 2014. Short-term effects of electronic and tobacco cigarettes on exhaled nitric oxide. Toxicol Appl Pharmacol, 278, 9-15.

MEGSON, I. L., HAW, S. J., NEWBY, D. E. \& PELL, J. P. 2013. Association between exposure to environmental tobacco smoke and biomarkers of oxidative stress among patients hospitalised with acute myocardial infarction. PLoS One, 8, e81209.

METSIOS, G. S., FLOURIS, A. D., JAMURTAS, A. Z., CARRILLO, A. E., KOURETAS, D., GERMENIS, A. E., GOURGOULIANIS, K., KIROPOULOS, T., TZATZARAKIS, M. N., TSATSAKIS, A. M. \& KOUTEDAKIS, Y. 2007. A brief exposure to moderate passive smoke increases metabolism and thyroid hormone secretion. J Clin Endocrinol Metab, 92, 208-11.

METTA, S., BASALINGAPPA, D. R., UPPALA, S. \& MITTA, G. 2015. Erythrocyte Antioxidant Defenses Against Cigarette Smoking in Ischemic Heart Disease. J Clin Diagn Res, 9, BC08-11.

MOJTABA, W., DAVOOD, K. \& HUSSEIN, D. 2014. Lower Total Antioxidant Capacity in Smokers Compare to

Non-smokers. Biological Forum - An International Journal, 6, 305-309.

MORIARTY, S. E., SHAH, J. H., LYNN, M., JIANG, S., OPENO, K., JONES, D. P. \& STERNBERG, P. 2003. Oxidation of glutathione and cysteine in human plasma associated with smoking. Free Radic Biol Med, 35, 1582-8. 
OZGUNER, F., KOYU, A. \& CESUR, G. 2005. Active smoking causes oxidative stress and decreases blood melatonin levels. Toxicol Ind Health, 21, 21-6.

PETRUZZELLI, S., PUNTONI, R., MIMOTTI, P., PULERA, N., BALIVA, F., FORNAI, E. \& GIUNTINI, C. 1997. Plasma 3-nitrotyrosine in cigarette smokers. Am J Respir Crit Care Med, 156, 1902-7.

PIGNATELLI, B., LI, C. Q., BOFFETTA, P., CHEN, Q., AHRENS, W., NYBERG, F., MUKERIA, A., BRUSKEHOHLFELD, I., FORTES, C., CONSTANTINESCU, V., ISCHIROPOULOS, H. \& OHSHIMA, H. 2001. Nitrated and oxidized plasma proteins in smokers and lung cancer patients. Cancer Res, 61, 77884.

PISINGER, C. \& DOSSING, M. 2014. A systematic review of health effects of electronic cigarettes. Prev Med, 69, 248-60.

REDDY, Y. N., MURTHY, S. V., KRISHNA, D. R. \& PRABHAKAR, M. C. 2004. Role of free radicals and antioxidants in tuberculosis patients. Ind J Tuberculosis, 51, 213-218.

RUBENSTEIN, D. A., HOM, S., GHEBREHIWET, B. \& YIN, W. 2015. Tobacco and e-cigarette products initiate Kupffer cell inflammatory responses. Mol Immunol, 67, 652-60.

SCHEFFLER, E., WIEST, E., WOEHRLE, J., OTTO, I., SCHULZ, I., HUBER, L., ZIEGLER, R. \& DRESEL, H. A. 1992. Smoking influences the atherogenic potential of low-density lipoprotein. Clin Investig, 70, 263-8.

SIES, H. \& CADENAS, E. 1985. Oxidative stress: damage to intact cells and organs. Philos Trans $R$ Soc Lond B Biol Sci, 311, 617-31.

VALKONEN, M. \& KUUSI, T. 1998. Passive smoking induces atherogenic changes in low-density lipoprotein. Circulation, 97, 2012-6.

VARDAVAS, C. I., ANAGNOSTOPOULOS, N., KOUGIAS, M., EVANGELOPOULOU, V., CONNOLLY, G. N. \& BEHRAKIS, P. K. 2011. Acute pulmonary effects of using an e-cigarette: impact on respiratory flow resistance, impedance and exhaled nitric oxide. Chest.

VARLET, V., FARSALINOS, K., AUGSBURGER, M., THOMAS, A. \& ETTER, J. F. 2015. Toxicity assessment of refill liquids for electronic cigarettes. Int J Environ Res Public Health, 12, 4796-815.

WORLD HEALTH ORGANISATION 2010. WHO Regulatory Consultation on the Safety of Electronic Nicotine Delivery Devices (ENDS). Geneva: World Health Organisation.

YILDIZ, L., KAYAOGLU, N. \& AKSOY, H. 2002. The changes of superoxide dismutase, catalase and glutathione peroxidase activities in erythrocytes of active and passive smokers. Clin Chem Lab Med, 40, 612-5.

ZHOU, J. F., YAN, X. F., GUO, F. Z., SUN, N. Y., QIAN, Z. J. \& DING, D. Y. 2000. Effects of cigarette smoking and smoking cessation on plasma constituents and enzyme activities related to oxidative stress. Biomed Environ Sci, 13, 44-55. 
1

2

3

4

5

6

7

8

10

11

12

13

14

15

16

17

18

19

20

21

22

23

24

25

26

27

28

29

30

31

32

33

34

35

36

37

38

39

40

41

42

43

44

45

46

47

48

49

50

51

52

53

54

55

56

57

58

59

60

\section{LIST OF FIGURES}

462 Figure 1. Electronic cigarette components.

463

464 Figure 2. Glutathione (GSH) levels (mean \pm SD) following active (A) and passive smoking (B).

465

466 Figure 3 Catalase activity (mean \pm SD) following active $(A)$ and passive smoking (B).

467

468 Figure 4. Total antioxidant activity (TAC) levels (mean $\pm S D$ ) following active (A) and passive smoking (B). 


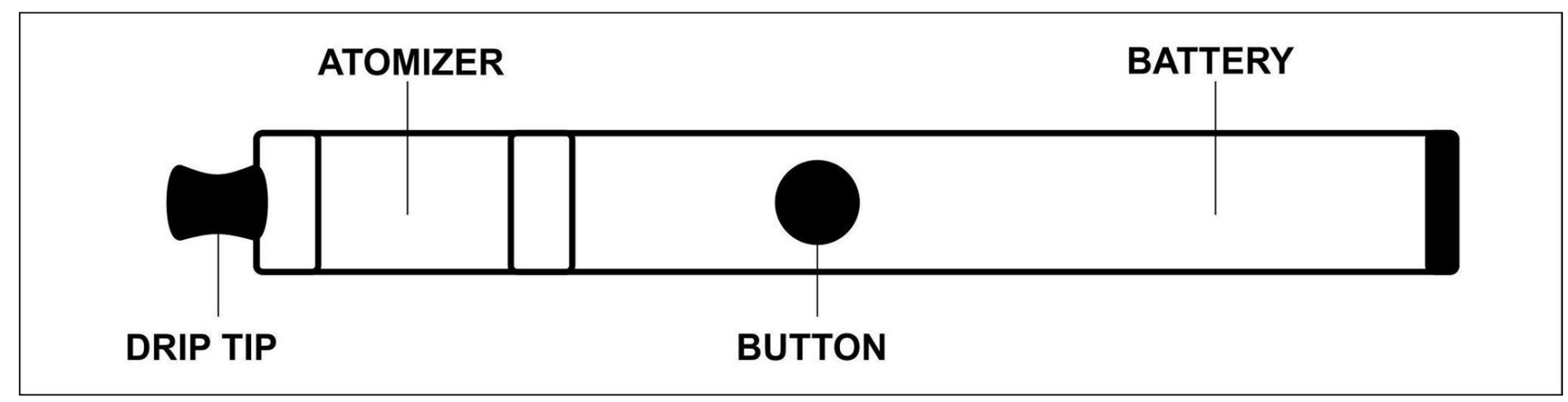




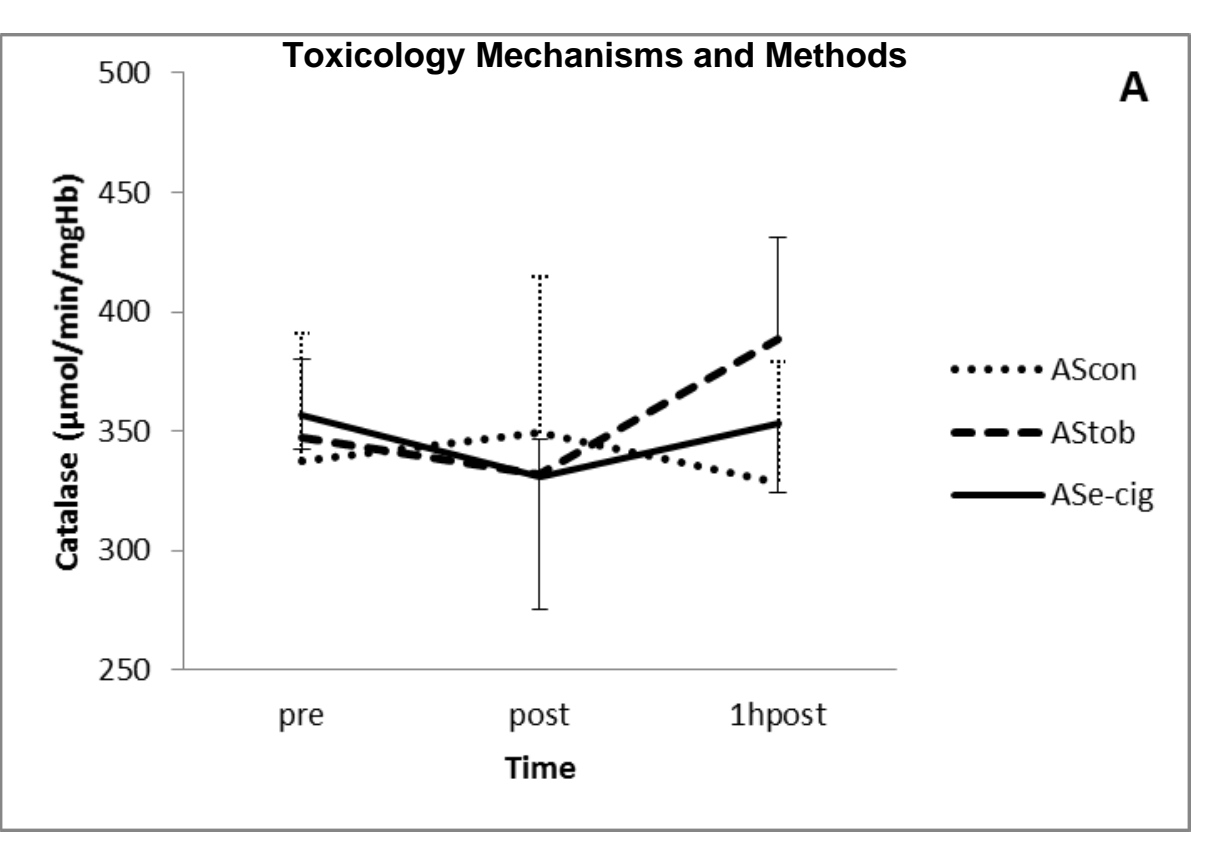

Page 28 of 29

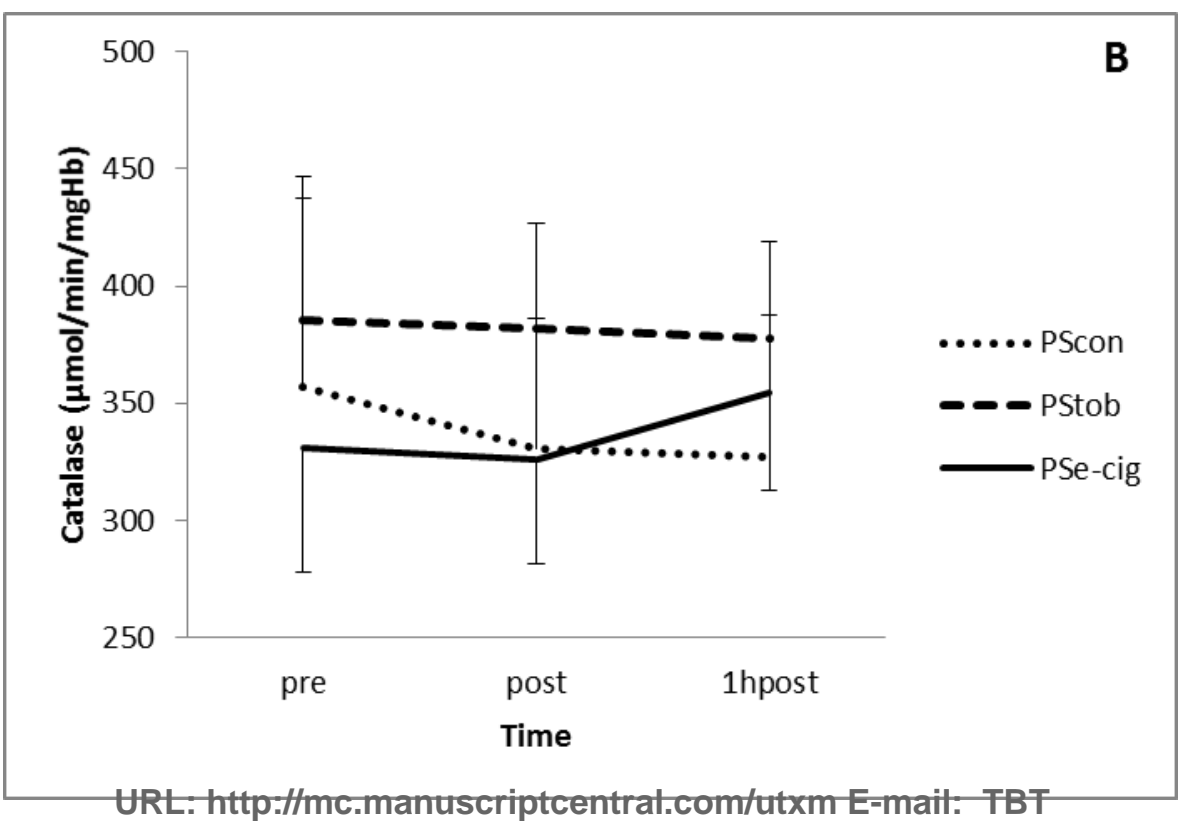



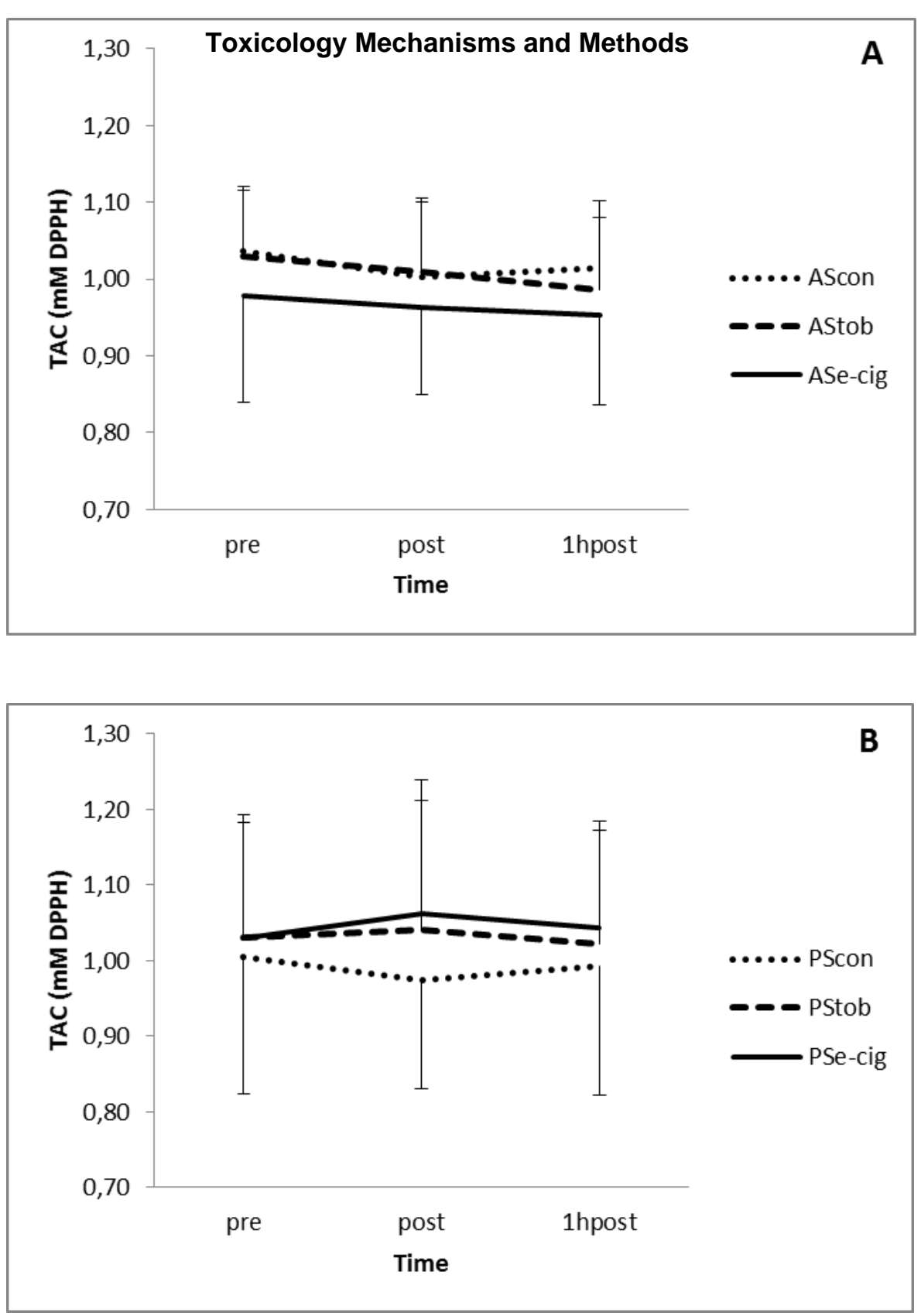

URL: http://mc.manuscriptcentral.com/utxm E-mail: TBT 